\title{
palgrave
}

Explaining the Negative Correlation between Values and Practices: A Note on the Hof stede-Globe Debate

Author(s): Robbert Maseland and André van Hoorn

Source: Journal of International Business Studies, Vol. 40, No. 3 (Apr., 2009), pp. 527-532

Published by: Palgrave Macmillan Journals

Stable URL: http://www.jstor.org/stable/40262839

Accessed: 31/07/2014 08:42

Your use of the JSTOR archive indicates your acceptance of the Terms \& Conditions of Use, available at http://www.jstor.org/page/info/about/policies/terms.jsp

JSTOR is a not-for-profit service that helps scholars, researchers, and students discover, use, and build upon a wide range of content in a trusted digital archive. We use information technology and tools to increase productivity and facilitate new forms of scholarship. For more information about JSTOR, please contact support@ jstor.org. 


\section{Explaining the negative correlation between values and practices: A note on the Hofstede-GLOBE debate}

\section{Robbert Maseland and André van Hoorn}

Institute for Management Research, Radboud University Nijmegen, Nijmegen, The Netherlands

\section{Correspondence:}

R Maseland, Radboud University Nijmegen, Institute for Management Research, PO Box 9108, Nijmegen NL-6500 HK,

The Netherlands.

Tel: + 31243611564 ;

Fax: + 31243612379

E-mail: R.Maseland@fm.ru.nl

\begin{abstract}
This note provides an explanation for the presumably counterintuitive, negative correlations between values and practices reported by the Global Leadership and Organizational Behavior Effectiveness project. We argue that such results are compatible with basic microeconomic insights concerning diminishing marginal utility. This explanation implies that values surveys, as they are, generally elicit marginal preferences rather than underlying values. Therefore they are a problematic instrument for the measurement of cultures, and need to be improved so as to discriminate between the importance attached to an objective in general and that attached to it given current levels of satiation.
\end{abstract}

Journal of International Business Studies (2009) 40, 527-532. doi: 10.1057/jibs.2008.68

Keywords: cross-cultural research/measurement issues; cultural dimensions; cultura frameworks; cultural values; GLOBE; Hofstede

\section{INTRODUCTION}

In an interesting special feature, this journal recently hosted a discussion centering on the differences between Geert Hofstede and the researchers involved in the GLOBE (Global Leadership and Organizational Behavior Effectiveness) project concerning the right approach to measuring culture (Earley, 2006; Hofstede, 2006; Javidan, House, Dorfman, Hanges, \& Sully de Luque, 2006; Leung, 2006; Smith, 2006). One of the main issues in this "clash of the titans," as the editor called it, is the validity of and rationale for the GLOBE study's attempt to measure practices and values simultaneously. ${ }^{1}$

In Hofstede's perspective, values drive practices. He visualizes this relationship in the so-called "Onion Diagram" (Hofstede, 2001: 11). Values, according to this diagram, are the most deeply rooted aspects of a culture, forming the basis for cultural practices. If this "onion assumption" is indeed correct, we should expect a positive correlation between cultural values and practices. Here the differences between Hofstede and the GLOBE project arise. Rather than assuming that knowing values tells us what actually happens in a culture, the GLOBE researchers decided to include both values and 
reported practices to identify different cultural dimensions of societies.

Strikingly, in no less than seven out of nine dimensions, the GLOBE team found a significant negative correlation between values and practices. Only one dimension showed a significant positive correlation. ${ }^{2}$ The authors of GLOBE call this result "both counterintuitive and counter to conventional wisdom" (Javidan et al., 2006: 901), and to them it is basically "unclear why the relationship should be negative rather than positive" (House, Hanges, Javidan, Dorfman, \& Gupta, 2004: 729). They conclude that the relationship between values and practices must be much more complex than Hofstede's Onion Diagram suggests (House et al., 2004: 730; Javidan et al., 2006: 902). Hofstede (2006) retorts that the "counterintuitive" result is due to design flaws in the questionnaires used in the GLOBE study, arguing that respondents are unable to describe practices independent of their values.

In this note, we argue that the presumably counterintuitive results of the GLOBE study do not evidence either those kinds of design flaws to which Hofstede (2006) alludes or that type of high complexity to which the authors of the GLOBE study refer. On the contrary, we argue that they can be explained by basic textbook microeconomics. The negative correlation between practices and values can be traced back to one of the core principles of modern economics: the law of diminishing marginal utility. Such an interpretation of the research implies that the project of measuring values by means of surveys - whether they be Hofstede's or GLOBE's - suffers from some serious problems. More specifically, the results reported by GLOBE indicate that values surveys fail to measure cultural values, and capture marginal preferences instead.

\section{WHY PRACTICES AND VALUES CORRELATE NEGATIVELY}

The GLOBE study questionnaire included two types of questions. ${ }^{3}$ On the one hand, respondents were asked how things were done in their society ("as is" questions). The GLOBE study refers to these items as "practices." On the other hand, the questionnaire included "should be" questions, each one corresponding to an "as is" question. The GLOBE study refers to "should be" items as "values." To exemplify, a value and practice question relating to

the power distance dimension is:

Practices

1.26 In this society, people in positions of power try to

increase their social

distance from less

powerful individuals

123

decrease their social distance from less powerful individuals 567

Values

3.28 I believe that people in positions of power should try to

increase their social distance from less powerful individuals

123 distance from less powerful individuals

At first sight, one might expect the answers to these questions to be positively correlated. If people in a society generally believe that there should be little distance between the powerful and the less powerful, one might think that their society would indeed be characterized by relatively little such distance. The idea that people acting upon their values are likely to produce a society that is in line with their values (the onion assumption) seems intuitively plausible. However, as mentioned, the GLOBE study reports negative correlations between practices and values. How is this possible?

Let us take the above two questions, but replace "their social distance from less powerful individuals" with "society's consumption of bread." This obtains:

Practices

In this society, people in positions of power try to

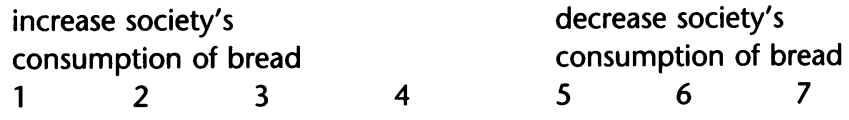

Values

I believe that people in positions of power should try to

increase society's

consumption of bread

$1 \quad 2 \quad 3$

We can use these alternative questions to explain negative correlations between practices and values as follows. To start, think of a society in which the 
government, for some reason, has one preoccupation: taking bread away from citizens and destroying it. In that case, when asked, people are likely to indicate that people in power are trying to decrease society's consumption of bread. At the same time, confronted with bread shortages due to this government policy, people will probably argue that those in power should increase the consumption of bread by citizens instead. Now think of that same country, but this time the government has reversed its policy: it taxes many activities heavily and uses the funds to buy bread for the public. Awash with bread, people would now probably indicate that those in power should try to decrease the consumption of bread rather than increase it. Different answers will thus be given by the same society and the same culture, even when only the circumstances have changed.

What this example shows is that the relative importance people attach to the consumption of commodities declines with the amount they have at their disposal. Receiving a million loaves of bread each day, even the most dedicated bread-a-holic is likely to favor a jar of peanut butter over another piece of bread. In economic terms, bread faces diminishing marginal utility. ${ }^{4}$ The principle of diminishing marginal utility explains the negative relation between practices and values reported by the GLOBE team. If an objective, say consuming bread, is satiated, the value one attaches to the realization of that objective falls. ${ }^{5}$ By contrast, that which is scarce - be it bread, butter, law and order, or equality - is generally valued highly. There is nothing counterintuitive about this.

Interestingly, a similar argument has been invoked by that other "titan" in cultural values surveys, Ronald Inglehart. Inglehart (e.g., 1990, 1997) claims that the principle of diminishing marginal utility is the major mechanism behind the value shift he observes in industrial societies. According to him, the decreasing value attached to the realization of materialist goals in industrial societies can be explained by the increased satiation of materialist objectives due to economic growth. ${ }^{6}$ The GLOBE team's hypothesis that some form of deprivation causes the observed negative correlations between values and practices (Javidan et al., 2006: 902) might, with some effort, be interpreted in the same way. However, the GLOBE authors remain vague about the mechanisms, and do not explicitly link this to the well-understood principles of satiation and diminishing marginal utility. Hence their conclusion reads only that, as stated above, the relationship between values and practices is highly complex. What is more, neither Inglehart nor the GLOBE team seems to be aware of the wider implications of their arguments. These implications are that, in so far as the data they provide indeed are subject to diminishing marginal utility, values surveys fail to measure values. We will explain the reasons for this below.

\section{WHAT DID GLOBE REALLY MEASURE? OR HOFSTEDE, FOR THAT MATTER}

In standard consumer theory individuals are assumed to have certain objectives. Let us say these are to consume bread and to have ("consume") rules and laws. These objectives enter the utility function of the individual with different weights. For example, an individual might in general find the consumption of bread more important than that of laws, thus attaching a stronger weight to bread than to laws. This obviously does not mean that the individual will always choose bread over laws. Whether the individual's priority lies with bread or laws hinges on the present consumption of both. In situations of lawlessness and ample bread the individual is likely to prefer laws. In the reverse situation, he or she will prefer bread.

The crucial difference here is the one between relative weights in the utility function and marginal preferences. The marginal preference for bread (laws) is the value the individual attaches to one more unit of bread (law) given the current endowment of bread (laws). Relative weights, on the other hand, refer to how much value the individual attaches to bread and laws, regardless of current endowment levels. Weights do not change with satiation; one's general inclinations towards bread are not dependent on the current consumption levels of bread. Marginal preferences, in contrast, do. The more bread one consumes, the less importance one attaches to consuming still more bread.

Values, if one follows for example Hofstede's definition as "broad tendencies to prefer certain states of affairs over others" (Hofstede, 2001: 5), correspond to relative weights. Yet this is not what values surveys appear to measure. The results from the GLOBE project show that values correlate negatively with practices, which indicates that these surveys primarily elicit marginal preferences rather than relative weights. That is, values surveys by and large measure how much importance society attaches to somewhat more bread (laws) than there is in the current situation. ${ }^{7}$ This is 
something rather different from the "broad tendencies" Hofstede seeks to measure.

Marginal preferences on the one hand and values, that is, relative weights, on the other hand are indeed two very different things. Measuring the one tells us nothing about the other. Marginal preferences can change without the weights in the utility function changing: the same person when living on an ounce of bread a day is likely to have a stronger marginal preference for bread than when being provided with 20 loaves a day. Similarly, two persons with very different utility functions can end up with the same marginal preferences: someone disliking bread, but consuming little of it, might marginally value bread just as much as a big bread fan who has already consumed so much bread as to cause nausea. Hence, in so far as values surveys elicit marginal preferences, any information they contain about values is strictly accidental.

\section{DISCUSSION AND CONCLUSION}

The negative correlation between values and practices reported by GLOBE is not such a puzzle as might appear at first sight. These findings are perfectly compatible with fundamental microeconomic insights concerning diminishing marginal utility: the more an objective is satiated, the less we value the further realization of that objective. In this interpretation of the results, Hofstede's onion assumption is not invalidated by GLOBE's findings. What this explanation does imply, however, is a reinterpretation of data from values surveys items as very likely measuring marginal preferences rather than underlying values.

That is not to say that, apart from the marginal preferences explanation for GLOBE's findings, other mechanisms could not play a role as well. Value change could be a factor, when previously held values tend to linger in society's practices. Hofstede's (2006: 886) argument that people tend to criticize their society from an ideological point of view also provides a possible additional mechanism. A tendency of respondents to highlight the contrast between the desired ("should be") and the actual ("as is") situation in their description of practices could account for a gap between practices and values. Moreover, measurement errors could simply play a role. However, it should be noted that explanations for GLOBE's findings require not only a mechanism resulting in a difference between reported values and practices, but also a mechanism bringing about negative correlations between the two. None of the above arguments can account for such a systematically negative correlation. Hofstede's contrasting mechanism implies only that respondents report practices different from their values; value change implies only that previous values (and hence current practices) are different from present values. There is no reason why such differences between practices and values would not be randomly distributed.

In contrast, our understanding of values surveys provides a theoretically and intuitively highly plausible explanation for the presumably "counterintuitive" results reported by the GLOBE team. In fact, if one had been willing to test the marginal preferences hypothesis prior to this discussion, the GLOBE results would have been very strong evidence in favor. That being said, it should be noted that for one dimension GLOBE found positive correlations between what it called values and practices, and for another it found no significant correlation at all. Hence it seems that marginal preferences are an important part of what values surveys designed as in the GLOBE project capture, but apparently not always to the extent that they dominate the findings. ${ }^{8}$ Values surveys are likely to capture both values and marginal preferences, but in unknown proportions. As a result, when conducting values surveys, one never knows for sure what one is measuring.

These problems are not easily solvable, although there is room for improvement upon the present situation. If we stick to the survey approach to value measurement, the challenge is to design questions that are less likely to be dominated by marginal preferences. In other words, questions should induce respondents to talk about their general inclinations rather than about changes to their present situation. This requires formulations such that respondents are likely to ignore the present context in their answers as much as possible. Moreover, questions should focus on desired states (the things weights are about) rather than desired changes (the subject of marginal preferences). As an example of a value question we think is less prone to elicit marginal preferences, we propose the following format:

Imagine that your current society no longer exists and that you are faced with a choice between four other societies in which to live. The societies differ only in the degree of protection of freedoms and the degree of equality. Please indicate the society in which you 
would most like to live by circling the corresponding number (1 to 4$)$ :

\begin{tabular}{lll}
\hline & Freedom & Equality \\
\hline 1. & Very free & Very unequal \\
2. & Rather free & Rather unequal \\
3. & Not very free & Rather equal \\
4. & Not at all free & Very equal \\
\hline
\end{tabular}

Such a format allows people to choose between a number of mutually exclusive worlds in which to live rather than between marginal changes to their current situation. Thereby it goes a long way in addressing the problems discussed in this note. However, even this question is not likely to be completely immune to distortion by marginal preferences, as we can never expect people to completely disregard their current situation in their answers. Marginal preferences will thus probably continue to be an issue.

To conclude, the GLOBE study illustrates that the problems outlined in this note have to be taken seriously. Almost a quarter century after Hofstede's seminal contribution, the GLOBE team's thorough and innovative study can therefore be applauded for, unintentionally, highlighting some of the so far neglected difficulties with the values surveys approach to measuring culture. There is much to be learned from values surveys as they are, but improving them so they can better discriminate between marginal preferences and underlying values is a major challenge for the future. It is one in which Hofstede and the GLOBE team can find each other.

\section{ACKNOWLEDGEMENTS}

Helpful comments by Sjoerd Beugelsdijk and EstherMirjam Sent are gratefully acknowledged. The paper has benefited from the comments of three anonymous referees. Needless to say, the views expressed in this paper are the authors' only.

\section{NOTES}

${ }^{1}$ The Hofstede-GLOBE debate adds to a large literature scrutinizing the survey approach in measuring values. This literature focuses on measurement methods (Flanagan, 1982a, b; Haller, 2002), the number of factor dimensions identified (Flanagan, 1982a, b; Maclntosh, 1998), micro-macro distinctions and the focus on the national level (Davis \& Davenport, 1999; Haller, 2002; McSweeney 2002a, b;
Silver \& Dowley, 2000), or the distinction between salience and underlying values (Clarke, Kornberg, McIntyre, Bauer-Kaase, \& Kaase, 1999). For a general overview of criticisms - and counterarguments - that have been leveled against the values surveys method see Søndergaard (1994) or Hofstede (2001: 73, 2002: 1356).

${ }^{2}$ The dimensions showing a negative correlation are assertiveness $(r=-0.26)$, institutional collectivism $(-0.61)$, future orientation $(-0.41)$, humane orientation $(-0.32)$, performance orientation $(-0.28)$, power distance $(-0.43)$, and uncertainty avoidance $(-0.62)$. All these correlations were significant at the $5 \%$ level. The only dimension showing a significantly positive correlation was gender egalitarianism $(r=0.32)$ (House et al., 2004, Appendix Table A.3: 736). Finally, in-group collectivism shows a positive but insignificant correlation.

${ }^{3}$ The questionnaires used in the GLOBE project are available from the project's website: http:// www.thunderbird.edu/wwwfiles/ms/globe/instruments. asp.

${ }^{4}$ Alfred Marshall explained the principle of diminishing marginal utility thus: "There is an endless variety of wants, but there is a limit to each separate want. This familiar and fundamental tendency of human nature may be stated in the law of satiable wants or of diminishing utility thus: The total utility of a thing to anyone (i.e., the total pleasure or other benefit it yields him) increases with every increase in his stock of it, but not as fast as his stock increases. If his stock of it increases at a uniform rate the benefit derived from it increases at a diminishing rate. In other words, the additional benefit which a person derives from a given increase of his stock of a thing diminishes with every increase in the stock that he already has." (Marshall, 1920 [1890]: 78-79)

${ }^{5}$ Strictly speaking, it is only the value attached to the further realization of an objective that falls. See the next section for an elaboration of this point.

'Inglehart is unclear about whether diminishing marginal utility is a mechanism affecting values surveys in general, and seems to suggest its influence is limited to the materialism/postmaterialism dimension. Although it seems reasonable to invoke economic mechanisms to explain observed economic phenomena only, the GLOBE findings actually indicate that the principle of diminishing marginal utility has broader applicability. This in turn means that our reference to societal goals in terms of consumption goods is supported by the negative correlations between practices and values found by the GLOBE researchers. 
${ }^{7}$ To be exact, values surveys measure the average importance attached to somewhat more rule of law than presently experienced by individual members of society. In a strict sense, this is not exactly the same as the importance society attaches to somewhat more rule of law than members of society on average experience in the current situation, as we suggest here. However, the two are closely related and any difference is only quantitative, so that in practice the distinction appears insignificant enough to be ignored in survey research. We thank an anonymous referee for pointing out this distinction.

${ }^{8}$ Thus, in the case of a positive correlation, values (weights) appear to dominate the item, whereas in the case of negative correlations, marginal preferences do so. If neither is dominant, no significant correlations will be found.

\section{REFERENCES}

Clarke, H., Kornberg, A., Mcintyre, C., Bauer-Kaase, P., \& Kaase, M. 1999. The effect of economic priorities on the measurement of value change: New experimental evidence. American Political Science Review, 93(3): 637-647.

Davis, D. W., \& Davenport, C. 1999. Assessing the validity of the postmaterialism index. American Political Science Review, 93(3): 649-664.

Earley, P. C. 2006. Leading cultural research in the future: A matter of paradigms and taste. Journal of International Business Studies, 37(6): 922-931.

Flanagan, S. 1982a. Changing values in advanced industrial societies: Inglehart's silent revolution from the perspective of Japanese findings. Comparative Political Studies, 14(4): 403-444.

Flanagan, S. 1982b. Measuring value change in advanced industrial societies: A rejoinder to Inglehart. Comparative Political Studies, 15(1): 99-128.

Haller, M. 2002. Theory and method in the comparative study of values: Critique and alternative to Inglehart. European Sociological Review, 18(2): 139-158.

Hofstede, G. 2001. Culture's consequences (2nd ed.). Thousand Oaks, CA: Sage Publications.

Hofstede, G. 2002. Dimensions do not exist: A reply to Brendan McSweeney. Human Relations, 55(11): 1355-1361.

Hofstede, G. 2006. What did GLOBE really measure? Researchers' minds versus respondents' minds. Journal of International Business Studies, 37(6): 882-896.

House, R. J., Hanges, P. J., Javidan, M., Dorfman, P. W., \& Gupta, V. 2004. Culture, leadership and organizations: The GLOBE study of 62 societies. Thousand Oaks, CA: Sage Publications.

Inglehart, R. 1990. Culture shift in advanced industrial society. Princeton, N]: Princeton University Press.

Inglehart, R. 1997. Modernization and postmodernization: Cultural, economic, and political change in 43 societies. Princeton, NJ: Princeton University Press.

Javidan, M., House, R. J., Dorfman, P. W., Hanges, P. J., \& Sully de Luque, $M$. 2006. Conceptualizing and measuring cultures and their consequences: A comparative review of GLOBE's and Hofstede's approaches. Journal of International Business Studies, 37(6): 897-914.

Leung, K. 2006. Editor's introduction to the exchange between Hofstede and GLOBE. Journal of International Business Studies, 37(6): 881.

Maclntosh, R. 1998. Global attitude measurement: An assessment of the World Values Survey Postmaterialism Scale. American Sociological Review, 63(3): 452-464.
Marshall, A. 1920 [1890]. Principles of economics: An introductory volume (8th ed.). London: The Macmillan Press.

McSweeney, B. 2002a. Hofstede's model of national cultural differences and their consequences: $A$ triumph of faith - a failure of analysis. Human Relations, 55(1): 89-118.

McSweeney, B. 2002b. The essentials of scholarship: A reply to Geert Hofstede. Human Relations, 55(11): 1363-1372.

Silver, B., \& Dowley, K. M. 2000. Measuring political culture in multiethnic societies: Reaggregating the World Values Survey. Comparative Political Studies, 33(4): 517-550.

Smith, P. B. 2006. When elephants fight, the grass gets trampled: The GLOBE and Hofstede projects. Journal of International Business Studies, 37(6): 915-921.

Søndergaard, M. 1994. Hofstede's consequences: A study of reviews, citations and replications. Organization Studies, 15(3): 447-456.

\section{ABOUT THE AUTHORS}

Robbert Maseland is a senior researcher at the Department of Political Science of Radboud University Nijmegen. He obtained his $\mathrm{PhD}$ in economics at Radboud University Nijmegen. Research interests include economic history and institutions, cultural values, and political economy. He is currently writing a book about culture in economics, together with Dr. Sjoerd Beugelsdijk. He was born in and is a citizen of the Netherlands. E-mail: R.Maseland@fm.ru.nl.

André van Hoorn is working on his $\mathrm{PhD}$ at Radboud University Nijmegen. He studied economics at Tilburg University and has a degree in financial and economic policy making from Erasmus University, Rotterdam. Next to the study of cultural values in economics, his main research interest is subjective well-being and its determinants. Born in the Netherlands, he is a Dutch citizen. E-mail: A.vanHoorn@fm.ru.nl. 